\title{
Anabases
}

ANABASES Traditions et réceptions de l'Antiquité

$1 \mid 2005$

Varia

\section{Ann Moss, Les Recueils de lieux communs. Apprendre à penser à la Renaissance}

\section{Florence Bouchet}

\section{OpenEdition}

\section{Journals}

Édition électronique

URL : http://journals.openedition.org/anabases/1520

DOI : 10.4000/anabases. 1520

ISSN : 2256-9421

\section{Éditeur}

E.R.A.S.M.E.

\section{Édition imprimée}

Date de publication : 1 mars 2005

Pagination : 321-322

ISSN : 1774-4296

\section{Référence électronique}

Florence Bouchet, «Ann moss, Les Recueils de lieux communs. Apprendre à penser à la Renaissance », Anabases [En ligne], 1 | 2005, mis en ligne le 01 octobre 2011, consulté le 22 septembre 2020. URL http://journals.openedition.org/anabases/1520 ; DOI : https://doi.org/10.4000/anabases.1520

Ce document a été généré automatiquement le 22 septembre 2020.

(c) Anabases 


\title{
Ann Moss, Les Recueils de lieux communs. Apprendre à penser à la Renaissance
}

\author{
Florence Bouchet
}

\section{RÉFÉRENCE}

Ann Moss, Les Recueils de lieux communs. Apprendre à penser à la Renaissance, trad. de l'anglais ss la dir. de P. Eichel-Lojkine, Genève, Droz, 2002 [éd. originale : Oxford, 1996], « Titre courant » 23, $547 \mathrm{p}$.

$18 €$ / ISBN 2-600-00523-4

1 La rhétorique, notamment l'histoire des lieux communs, constitue un fil conducteur permettant de saisir un héritage de l'Antiquité en diachronie longue. Après avoir retracé la genèse des loci communes dans la rhétorique antique, A.M. en étudie l'usage et les fonctions jusqu'au XVII ${ }^{e}$ siècle, en France ainsi que dans d'autres pays européens.

Le corpus des auctoritates latines (païennes et ecclésiastiques - les recueils de lieux communs en langue vernaculaire, qui seraient l'objet d'une autre étude, également intéressante, ne sont que succinctement abordés) est suivi à travers la composition des florilèges médiévaux et des recueils ultérieurs de lieux communs, destinés principalement à l'enseignement et à la prédication. L'ouvrage complète efficacement celui, fameux mais désormais ancien, d'E.R. Curtius, La littérature européenne et le Moyen Âge latin (1948; trad. française, Paris, P.U.F., 1956). Alors que Curtius privilégiait une approche thématique (le contenu topique), A.M. explore la notion de lieu commun en tant que genre, outil de pensée. À cet effet, un utile florilège (comme il se devait!) de 256 citations latines (de Cicéron à Descartes) fourni en appendice complète les analyses d'A.M. et permet de suivre le discours sur les lieux communs (sa propre topique, ses infléchissements). 
3 Procédé argumentatif et ornemental, le geste topique éclaire un pan de l'histoire culturelle qu'on ne saurait qualifier de secondaire en des siècles où l'écriture, fondée sur l'allégation d'autorités et sur leur imitation, justifiait pleinement ces commodes relais de lecture que constituaient les recueils de lieux communs. Les loci communes s'intègrent naturellement dans le programme culturel humaniste mais sont aussi récupérés dans la controverse religieuse du XVI ${ }^{e}$ siècle, en raison de l'important fonds biblique et patristique figurant dans ces recueils. Ces compilations des meilleurs auteurs rassuraient également au moment où « l'explosion de l'imprimé » confrontait à la possibilité, sinon la nécessité, de lire de nombreux ouvrages. Au cours du XVII siècle, malgré la place importante qu'y tient l'art oratoire (juridique ou religieux), s'amorce néanmoins le déclin du genre : la notion de propriété d'auteur s'affirme, la logique de Port-Royal réfute comme artificielle les démonstrations fondées sur les catégories topiques, Descartes récuse l'autorité livresque des Anciens pour affermir la validité de son propre raisonnement.

4 Ceci ne donne qu'un aperçu lacunaire de la façon dont A.M. analyse les raisons du succès puis du discrédit des collection de lieux communs qui, indéniablement, constituèrent un instrument rhétorique et un outil pédagogique de premier plan pour le façonnement des esprits jusqu'à l'âge classique. On aurait certes aimé pouvoir suivre aussi de l'intérieur le contenu de cet enseignement : savoir concrètement ce qui, chez les grands auteurs de référence, était sélectionné ; suivre l'évolution de la « cote » des auteurs. Mais cette entreprise considérable nécessite une autre étude, de la part d'A.M. ou d'autres chercheurs. On peut enfin regretter l'absence d'une bibliographie générale en fin de volume (les références sont disséminées et commentées dans les notes infrapaginales). Les lecteurs de l'ouvrage intégral seront donc récompensés, ultime preuve, en dépit d'un index détaillé, qu'une lecture sélective, choisissant certains loci, n'est plus suffisante...

\section{AUTEURS}

\section{FLORENCE BOUCHET}

Université de Toulouse-Le Mirail 